Heins, M., Knoop, H., Nijs, J., Feskens, R., Meeus, M., Moorkens, G., Bleijenberg, G. Influence of symptom expectancies on stair-climbing performance in chronic fatigue syndrome: effect of

\begin{tabular}{|l|l|}
\hline $\begin{array}{l}\text { Postprint } \\
\text { Version }\end{array}$ & 1.0 \\
\hline Journal website & http://link.springer.com/article/10.1007/s12529-012-9253-2 \\
\hline Pubmed link & $\underline{\text { http://www.ncbi.nlm.nih.gov/pubmed/22865100 }}$ \\
\hline DOI & $10.1007 /$ s12529-012-9253-2 \\
\hline
\end{tabular}

This is a NIVEL certified Post Print, more info at http://www.nivel.eu

\title{
Influence of Symptom Expectancies on Stair- Climbing Performance in Chronic Fatigue Syndrome: Effect of Study Context
}

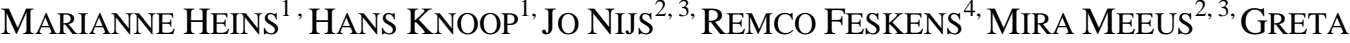 \\ MOORKENS $^{5}$ AND GIJS BLEIJENBERG ${ }^{1}$ \\ ${ }^{(1)}$ Expert Centre for Chronic Fatigue, Radboud University Nijmegen Medical Centre, 4628, \\ PO Box 9101, 6500, HB, Nijmegen, The Netherlands \\ (2) Department of Human Physiology, Faculty of Physical Education and Physiotherapy, Vrije \\ Universiteit Brussel, Brussels, Belgium \\ (3) Division of Musculoskeletal Physiotherapy, Department of Health Care Sciences, Artesis \\ University College Antwerp, Antwerp, Belgium \\ (4) Department of Methods and Statistics, Utrecht University, Utrecht, The Netherlands \\ ${ }^{(5)}$ Reference Centre for Chronic Fatigue Syndrome, University of Antwerp,
}

\begin{abstract}
Background: In patients with chronic fatigue syndrome (CFS), performance of physical activities may be affected by an anticipated increase in symptoms after these activities. Nijs et al. previously studied the influence of symptom expectancies and related psychological processes on the performance of an isolated physical activity [Nijs J, Meeus M, Heins M, Knoop H, Moorkens G, Bleijenberg G. Kinesiophobia, catastrophizing and anticipated symptoms before stair climbing in chronic fatigue syndrome: an experimental study. Disabil Rehabil 2012. doi:10.3109/09638288.2011.641661.].

Purpose: We aimed to validate the previous findings in a larger group of patients in a different setting. We also extended the possible underlying psychological processes studied.

Method: In 49 CFS patients, we measured performance (duration and increase in heart rate) during self-paced climbing and descending of two floors of stairs. Before this task, patients rated experienced fatigue and anticipated fatigue after stair climbing. In addition, kinesiophobia, catastrophising and focusing on bodily symptoms were measured. Using correlational and regression analyses, we tested whether performance during stair climbing could be explained by experienced and anticipated fatigue and psychological factors.

Results: Longer duration of stair climbing correlated with higher anticipated fatigue, independently of sex, age, body mass index and fatigue before stair
\end{abstract}


Heins, M., Knoop, H., Nijs, J., Feskens, R., Meeus, M., Moorkens, G., Bleijenberg, G. Influence of symptom expectancies on stair-climbing performance in chronic fatigue syndrome: effect of

climbing. Focusing on bodily symptoms and fatigue-related catastrophising were related to anticipated fatigue.

Conclusion: Symptom expectations affect the performance of physical activity in CFS patients, possibly through focusing on bodily symptoms and catastrophising. These findings partially contradict the findings of the previous study, which stresses the importance of study context in conducting this type of experiments (i.e., patient characteristics, instructions).

\section{INTRODUCTION}

Chronic fatigue syndrome (CFS) is defined by severe, debilitating fatigue that is medically unexplained and lasts longer than 6 months $\left[{ }^{1}\right]$. Another defining feature of CFS is postexertional malaise, i.e., vigorous exercise may trigger a substantial increase in symptoms $\left[{ }^{2}-{ }^{4}\right]$. So it seems evident for patients with CFS to expect an increase in fatigue after physically demanding activities. Anticipated fatigue may influence how patients perform a physical activity $\left[^{2}\right]$. Patients who expect an increase in fatigue after a particular task may avoid that task. Indeed, one study in CFS patients found that fatigue expectations for daily activities correlated with the frequency of performing those activities $\left[{ }^{5}\right]$. Instead of avoiding a task, patients may also perform it less vigorously. Beliefs concerning activity and anticipated fatigue may also play important roles in CBT as one of the goals in this treatment is to improve daily functioning. Further insight into the role of these factors in CFS may therefore also help to optimise existing protocols of behavioural interventions and training programs for CFS.

We previously investigated the influence of symptom expectancies, momentary symptoms and several psychological factors on performance of an isolated physical task, i.e., stair climbing $\left[^{6}\right]$. In that study, we found that the psychological factors kinesiophobia and catastrophising about fatigue were related to performance of physical activity in CFS. Kinesiophobia is defined as "an excessive, irrational, and debilitating fear of physical movement and activity resulting from a feeling of vulnerability to painful injury or reinjury" $\left[{ }^{7}\right]$ and catastrophising as a lack of confidence and a tendency to expect negative outcomes. Both have been reported to be common in CFS patients $\left[{ }^{8}-{ }^{10}\right]$ and have been related to maximal physical performance and level of fatigue and disabilities $\left[{ }^{8},{ }^{10}-{ }^{12}\right]$.

Although the previous study resulted in some interesting findings, it was hampered by its small sample size $(n=21)$ and a diagnosis of CFS that was only based on clinical judgement and not supported by validated questionnaires. In addition, performance of stair climbing may have been influenced by factors, such as sex, age and body mass index (BMI), which were not controlled for in the previous study. We therefore tried to validate the previous findings by performing the same study in a larger group of Dutch CFS patients, where the diagnosis was based on validated questionnaires and data on possible confounders were gathered.

Besides the psychological factors kinesiophobia and catastrophising about fatigue, in the present study, we also examined the role of focusing on bodily symptoms. Focusing on bodily symptoms plays an important role in CFS. It is part of a model explaining the persistence of symptoms in CFS patients $\left[{ }^{13}\right]$ and mediation analyses 
Heins, M., Knoop, H., Nijs, J., Feskens, R., Meeus, M., Moorkens, G., Bleijenberg, G. Influence of symptom expectancies on stair-climbing performance in chronic fatigue syndrome: effect of

study context. International Journal of Behavioral Medicine: 2013, 20(2), 213-218

have shown that a decrease in focusing is related to the decrease in fatigue during cognitive behavioural therapy for CFS $\left[{ }^{14}\right]$. We therefore hypothesised that it would also play a role in performance of physical activity in CFS.

The aim of the current paper was thus to compare results of both studies and broaden the previous findings by testing whether stair climbing is also influenced by focusing on symptoms.

\section{METHODS}

\section{Patients}

Patients between 18 and 65 years who were referred to our tertiary expert centre for cognitive behaviour therapy (CBT) were informed about the study at the start of the standard diagnostic procedure. All patients had been subjected to an extensive medical evaluation, to rule out medical conditions that could explain the fatigue. To be included in the study, patients had to fulfil the Centers for Disease Control and Prevention criteria for CFS $\left[{ }^{1}\right]$. These criteria encompass severe, medically unexplained fatigue, lasting at least 6 months and resulting in severe limitations in daily functioning, next to four out of eight case-defining symptoms. Severe fatigue was defined as a score of at least 35 on the subscale 'fatigue severity' of the checklist individual strength (CIS) $\left[{ }^{13}\right]$, and severe functional limitations were defined as a total score of at least 700 on the Sickness Impact Profile $\left[{ }^{15}\right]$. In light of the physically demanding nature of the stair-climbing task, all subjects with heart, knee or back problems were excluded from the study. All participants gave written informed consent before participation. The study was conducted in accordance with the Helsinki declaration 1975, as revised in 2000, and the study protocol was approved by the local ethical committee.

\section{Measurements}

\section{Stair Climbing}

Subjects were instructed to climb two floors of stairs $(4 \times 8$ steps, height/depth 19.5 $\mathrm{cm})$ and then to descend to their starting position. They were instructed to perform the activity in their usual way (i.e., self-paced), but without resting periods during the task (patients were instructed not to wait on top of the stairs prior to descending). This self-paced method was chosen to ensure that performance of stair-climbing performance would resemble that of daily life.

We also measured the increase in heart rate during stair climbing. Increase in heart rate was defined as the difference between the heart rate after descending the last step of stairs and the baseline heart rate. Increase in heart rate was hypothesised to depend on momentary fatigue and to influence duration of stair climbing. Heart rate was measured using a polar ${ }^{\circledR}$ fs3c heart rate monitor. Baseline heart rate was measured right before stair climbing in standing position at the base of the stairs after a 1-min rest.

\section{Momentary and Anticipated Fatigue and Pain}

Right before stair climbing, the current level of fatigue and pain were measured on two visual analogue scales, with the question 'how much fatigue/pain do you experience right now' (range 0 'no fatigue/pain' to 100 'unbearable fatigue/pain’). 
Heins, M., Knoop, H., Nijs, J., Feskens, R., Meeus, M., Moorkens, G., Bleijenberg, G. Influence of symptom expectancies on stair-climbing performance in chronic fatigue syndrome: effect of

After filling in several other visual anologue scales measuring expected fatigue in other activities, patients were asked to rate their anticipated levels of fatigue and pain following two-floor stair climbing on a visual analogue scale (range 0 'no fatigue/pain' to 100 'unbearable fatigue/pain').

\section{Psychological Factors}

\section{Kinesiophobia}

Fatigue-related kinesiophobia was measured with the shortened version of the Tampa scale for fear of fatigue (TS-fatigue) $\left[{ }^{10}\right]$. The TS-fatigue is a scale based on the Tampa scale of kinesiophobia (TSK) in which the word 'pain' has been replaced with the word 'fatigue'. The scale has been translated in Dutch and has been used in a large population of CFS patients and patients with other conditions. Reliability of the scale is sufficient (Cronbach's alpha $=0.80)\left[{ }^{6}\right]$.

\section{Catastrophising}

The Jacobsen-fatigue catastrophising scale (J-FCS) is a ten-item scale measuring fatigue-related catastrophising $\left[{ }^{16}\right]$. Each item consists of a five-point Likert scale on which patients rate how often each item is true for them when they experience fatigue ( $1=$ 'never true' to $5=$ 'all of the time true'). A total score is computed by adding the items and dividing them by 10. In a sample of 844 CFS patients starting CBT at our centre, Cronbach’s alpha was 0.86 .

\section{Focusing on Symptoms}

Focusing on symptoms was measured with the subscale 'focusing on symptoms' of the illness management questionnaire $\left[{ }^{17}\right]$. This questionnaire measures the patient's approach to CFS in the last 6 months on a six-point Likert scale (ranging from 'never' to 'always'). The subscale focusing on bodily symptoms consists of nine items and the reliability in CFS patients is good (Cronbach's alpha $=0.88$ ).

\section{Statistics}

Data analysis was performed using SPSS for Windows ${ }^{\circledR}$ version 115.0.

We calculated Spearman correlations for duration of stair climbing with (1) anticipated pain and fatigue, (2) the difference between anticipated and experienced pain and fatigue and (3) the psychological variables kinesiophobia, catastrophising and focusing on symptoms. Significant correlations were then corrected for sex, age BMI and symptoms before stair climbing using multiple regression analysis.

Baseline characteristics and results of the stair-climbing task in the previous and current study were compared. As the previous study only included women, we made separate comparisons for women only.

\section{RESULTS}

\section{Baseline Characteristics}

In total, 61 patients were asked to participate, of which seven refused and five were excluded because of knee or back problems. Baseline characteristics of these 49 patients are listed in Table 1. In Table 2, descriptive statistics of the stair-climbing data are listed. 
Heins, M., Knoop, H., Nijs, J., Feskens, R., Meeus, M., Moorkens, G., Bleijenberg, G. Influence of symptom expectancies on stair-climbing performance in chronic fatigue syndrome: effect of

\section{[TABLE 1] [TABLE 2]}

\section{Are Symptom Expectancies and Psychological Variables Related to Stair- Climbing Performance in CFS?}

Results of the correlational analyses are given in Table 3. Stair-climbing duration correlated significantly with anticipated fatigue $(r=0.40 ; \mathrm{p}<0.001)$ and with the difference between anticipated and experienced fatigue $(r=0.30 ; p=0.04)$. We performed multiple regression analysis to control for sex, age, BMI and fatigue before stair climbing. Results are shown in Table 4. Even after controlling for these factors, anticipated fatigue after stair climbing was a strong predictor of the duration of stair climbing $(\mathrm{r}=0.30 ; \mathrm{p}<0.001)$. This model explained $21 \%$ of the variance (adjusted $\left.\mathrm{r}^{2}\right)$ in duration of stair climbing $(\mathrm{p}=0.008)$. When leaving out anticipated fatigue, the explained variance was $-0.05(\mathrm{p}=0.79)$.

\section{[TABLE 3][TABLE 4]}

\section{Comparison with Nijs et al. [ $\left.{ }^{6}\right]$}

The participants of the current study differed significantly from that of the previous study of Nijs et al. $\left[^{6}\right]$. Mean age was significantly lower and height significantly longer than in the previous study. In addition, mean level of fatigue and problems with physical activity as measured with the CIS were significantly higher. Baseline characteristics of the stair-climbing task also differed considerably. Duration of stair climbing was significantly shorter in the current study, and increase in heart rate was significantly higher when only women were compared. Experienced fatigue before stair climbing was similar, but experienced pain was significantly lower in the current study. Anticipated and experienced pain after stair climbing were also lower. Pain-related kinesiophobia was significantly lower in the current sample, whereas fatigue-related kinesiophobia and catastrophising were similar. Results of the statistical analyses differed also from the previous study (see Table 3), as kinesiophobia and catastrophising were not related to stair-climbing duration, while they were in the study of Nijs et al. Furthermore, we found a significant correlation between anticipated fatigue and stair-climbing duration, which was not found in the previous study.

\section{DISCUSSION}

The results of our current study show that the level of anticipated fatigue after physical activity is an important determinant of the performance of that activity. Before a physical activity, patients seem to assess how fatigued they will become and adjust the way they perform the activity accordingly. Fatigue expectations are influenced by fatigue catastrophising and the amount of focusing on bodily symptoms. The latter is an important perpetuating factor of fatigue in CFS $\left[{ }^{13}\right]$. These results confirm those of the paper of Nijs et al. $\left[^{6}\right]$ as they show that cognitive processes play a large role in performance of physical activities in CFS patients. However, in the current study, stair-climbing duration was primarily related to anticipated fatigue, while in the study of Nijs et al., it was related to kinesiophobia 
Heins, M., Knoop, H., Nijs, J., Feskens, R., Meeus, M., Moorkens, G., Bleijenberg, G. Influence of symptom expectancies on stair-climbing performance in chronic fatigue syndrome: effect of study context. International Journal of Behavioral Medicine: 2013, 20(2), 213-218

and catastrophising. This shows that performing the exact same protocol in a similar setting (i.e., tertiary reference centre for CFS) can lead to different results. What could explain these differences?

First of all, they may be due to differences in patient population. Patients in the previous study of Nijs et al. reported more pain symptoms and less fatigue. In fact, the correlation of expected pain with stair-climbing duration in their study was similar to that found for expected fatigue in the current (both $r=0.40$ ). Because of the lower sample size, the correlation between expected pain and stair climbing in the former study was not statistically significant. So also in the study of Nijs et al. symptom, expectancies seem to predict stair-climbing duration, but expectancies seemed to be more related to pain than fatigue.

Pain-related fear and catastrophising have been extensively studied in patients with chronic pain and are both part of the previously mentioned fear avoidance model for pain $\left[{ }^{18}\right]$. The study of Nijs et al. indicates that they also play a role in pain symptoms of patients with CFS. Fatigue-related catastrophising may play a more modest role in their fatigue symptoms. We also suppose that differences may be due to subtle differences in the instructions patients received. Despite consultation between the two experiment leaders of the study, participants in the study of Nijs et al. were instructed to climb the stairs in a comfortable way, while in the current study, they were instructed to climb the stairs in their usual way. Such seemingly small differences may have a large influence on the way patients perform a given task. There are several lessons to be learned from this study. First, it suggests that the CFS population is heterogenic $\left[{ }^{19}{ }^{21}\right]$, which is something researchers should be aware of. Care should therefore be taken when combining results of multicentre studies. Second, it points out that in studies trying to experimentally test psychological processes, performing the experiment together at least once and having detailed written instructions for the experiment leader are important. It is conceivable that many research papers do not report their instructions in such detail, which may make exact replication by other research groups even more difficult.

A limitation of our study is the relatively small sample size. This prevented us from performing more advanced statistical analyses; however, for the current analyses, sample size was sufficient. We did not perform corrections for multiple testing to keep our analyses similar to that of Nijs et al. Another weakness is that heart rate was displayed on a wristwatch that patients wore, so it was not in full sight, but they might have monitored it. Especially those with high anticipated fatigue may have done this and may have slowed their pace when they deemed it too high. Neither our current study nor that of Nijs et al. included a control group of healthy persons or a group of patients with another form of chronic fatigue. We therefore do not know whether our results are specific for CFS patients or are also applicable to healthy persons or other fatigued patient groups. This does, however, not invalidate our findings that symptom expectancies determine performance of a physical task in CFS patients.

Instead of objective performance, it would have been interesting to measure perceived effort. Interestingly, Baden et al. showed that perceived effort of exercise is dependent on expectations about the duration and thus anticipated effort. They even showed that perceived effort changes when expectations about the duration of exercise are altered $\left[{ }^{22}\right]$. Furthermore, focusing on bodily symptoms has also been related to perceived effort. Stanley et al. $\left[{ }^{23}\right]$ studied healthy subjects during a 
Heins, M., Knoop, H., Nijs, J., Feskens, R., Meeus, M., Moorkens, G., Bleijenberg, G. Influence of symptom expectancies on stair-climbing performance in chronic fatigue syndrome: effect of study context. International Journal of Behavioral Medicine: 2013, 20(2), 213-218

submaximal exercise test. Participants that were asked to focus on their bodily signals rated their level of perceived exertion significantly higher than subjects that were asked to focus on external signals, such as the duration of the exercise or other persons in the room. Perceived effort could therefore well be a mediating variable between either focusing on symptoms and objective performance or between expectations and objective performance.

Our findings underline the importance of cognitions related to physical activity in CFS. This has important implications for cognitive behavioural therapy and graded exercise therapy for CFS. Wiborg et al. $\left[{ }^{24}\right]$ recently found that the beneficial effect of cognitive behavioural therapy was not accomplished by improving physical activity. The positive effects of both cognitive behavioural therapy and graded exercise are mediated by a diminishing in focusing on bodily symptoms $\left[{ }^{14},{ }^{25}\right]$. Our results shed a light on how these cognitions may have an influence on daily activities in CFS patients.

\section{REFERENCES}

1. Fukuda K, Straus SE, Hickie I, Sharpe MC, Dobbins JG, Komaroff A. The chronic fatigue syndrome: a comprehensive approach to its definition and study. International Chronic Fatigue Syndrome Study Group. Ann Intern Med. 1994;121(12):953-9.

2. Bazelmans $E$, Bleijenberg G, Voeten $M J$, van der Meer JW, Folgering $H$. Impact of a maximal exercise test on symptoms and activity in chronic fatigue syndrome. J Psychosom Res. 2005;59(4):201-8.

3. Lapp CW. Exercise limits in chronic fatigue syndrome. Am J Med. 1997;103(1):83-4.

4. VanNess JM, Stevens SR, Bateman L, Stiles TL, Snell CR. Postexertional malaise in women with chronic fatigue syndrome. J Womens Health (Larchmt). 2002;19(2):239-44.

5. Vercoulen JH, Bazelmans E, Swanink CM, et al. Physical activity in chronic fatigue syndrome: assessment and its role in fatigue. J Psychiat Res. 1997;31(6):661-73.

6. Nijs J, Meeus M, Heins M, Knoop H, Moorkens G, Bleijenberg G. Kinesiophobia, catastrophizing and anticipated symptoms before stair climbing in chronic fatigue syndrome: an experimental study. Disabil Rehabil. 2012;doi:10.3109/09638288.2011. 641661.

7. Kori S, Miller R, Todd D. Kinesiophobia: a new view of chronic pain behavior. Pain Manage. 1990:35-43.

8. Nijs J, De Meirleir K, Duquet W. Kinesiophobia in chronic fatigue syndrome: assessment and associations with disability. Arch Phys Med Rehabil. 2004;85(10):1586-92.

9. Nijs J, Vanherberghen K, Duquet W, De Meirleir K. Chronic fatigue syndrome: lack of association between pain-related fear of movement and exercise capacity and disability. Phys Ther. 2004;84(8):696-705.

10. Silver A, Haeney M, Vijayadurai P, Wilks D, Pattrick M, Main CJ. The role of fear of physical movement and activity in chronic fatigue syndrome. J Psychosom Res. 2002;52(6):485-93.

11. Petrie K, Moss-Morris R, Weinman J. The impact of catastrophic beliefs on functioning in chronic fatigue syndrome. J Psychosom Res. 1995;39(1):31-7.

12. Nijs J, Van de Putte K, Louckx F, Truijen S, De Meirleir K. Exercise performance and chronic pain in chronic fatigue syndrome: the role of pain catastrophizing. Pain Med. 2008;9(8):1164-72.

13. Vercoulen JH, Swanink CM, Galama JM, et al. The persistence of fatigue in chronic fatigue syndrome and multiple sclerosis: development of a model. J Psychosom Res. 1998;45(6):507-17.

14. Wiborg JF, Knoop H, Prins JB, Bleijenberg G. Does a decrease in avoidance behavior and focusing on fatigue mediate the effect of cognitive behavior therapy for chronic fatigue syndrome? J Psychosom Res. 2011;70(4):306-10. 
Heins, M., Knoop, H., Nijs, J., Feskens, R., Meeus, M., Moorkens, G., Bleijenberg, G. Influence of symptom expectancies on stair-climbing performance in chronic fatigue syndrome: effect of

study context. International Journal of Behavioral Medicine: 2013, 20(2), 213-218

15. Bergner M, Bobbitt RA, Pollard WE, Martin DP, Gilson BS. The sickness impact profile: validation of a health status measure. Med Care. 1976;14(1):57-67.

16. Jacobsen PB, Azzarello LM, Hann DM. Relation of catastrophizing to fatigue severity in women with breast cancer. Cancer Res Ther Contr. 1999;8:155-64.

17. Ray C, Weir W, Stewart D, Miller P, Hyde G. Ways of coping with chronic fatigue syndrome: development of an illness management questionnaire. Soc Sci Med. 1993;37(3):385-91.

18. Vlaeyen JW, Linton SJ. Fear-avoidance model of chronic musculoskeletal pain: 12 years on. Pain. 2012. doi:10.1016/j.pain.2011.12.009.

19. Wilson A, Hickie I, Hadzi-Pavlovic D, et al. What is chronic fatigue syndrome? Heterogeneity within an international multicentre study. Aust N Z J Psychiatry. 2001;35(4):520-7.

20. Cella M, Chalder T, White PD. Does the heterogeneity of chronic fatigue syndrome moderate the response to cognitive behaviour therapy? An exploratory study. Psychother Psychosom. 2011;80(6):353-8. doi:10.1159/000327582.

21. Nisenbaum R, Reyes M, Unger ER, Reeves WC. Factor analysis of symptoms among subjects with unexplained chronic fatigue: what can we learn about chronic fatigue syndrome? J Psychosom Res. 2004;56(2):171-8. doi:10.1016/S0022-3999(03)00039-4.

22. Baden DA, McLean TL, Tucker R, Noakes TD, St Clair Gibson A. Effect of anticipation during unknown or unexpected exercise duration on rating of perceived exertion, affect, and physiological function. Br J Sports Med. 2005;39(10):742-6. discussion -6.

23. Stanley C, Pargman D, Tenenbaum G. The effect of attentional coping strategies on perceived exertion in a cycling task. J Appl Sport Psychol. 2007;19:352-63.

24. Wiborg JF, Knoop H, Stulemeijer M, Prins JB, Bleijenberg G. How does cognitive behaviour therapy reduce fatigue in patients with chronic fatigue syndrome? The role of physical activity. Psychol Med.40(8):1281-7.

25. Moss-Morris R, Sharon C, Tobin R, Baldi JC. A randomized controlled graded exercise trial for chronic fatigue syndrome: outcomes and mechanisms of change. J Health Psychol. 2005;10(2):245-59.

\section{TABLES}

Table 1 Baseline characteristics of the participants

\begin{tabular}{lllllc}
\hline Descriptive variable & Nijs et al. $(n=21)$ & Current study $(n=49)$ & $\begin{array}{l}p \text { Value Nijs } \\
\text { vs. current }\end{array}$ & $\begin{array}{l}\text { Current (women) } \\
(n=30)\end{array}$ & $\begin{array}{c}p \text { Value Nijs vs. } \\
\text { current (women) }\end{array}$ \\
\hline Sex(male) & 0 & 19 & & 0 & $\mathbf{0 . 0 0 1}$ \\
Age (years) & $44.7 \pm 10.5$ & $38.7 \pm 10.4$ & $\mathbf{0 . 0 3}$ & $34.7 \pm 9.8$ & 0.88 \\
Body weight (kg) & $69.6 \pm 13.8$ & $75.3 \pm 17.0$ & 0.15 & $69.0 \pm 14.8$ & 0.05 \\
Body length (cm) & $165.2 \pm 7.7$ & $175.6 \pm 10.8$ & $<\mathbf{0 . 0 0 1}$ & $169.6 \pm 8.0$ & \\
Illness duration (months) & $89.9 \pm 52.8$ & & & $49.7 \pm 5.5$ & $\mathbf{0 . 0 3}$ \\
CIS fatigue & $43.9 \pm 10.9$ & $49.6 \pm 5.3$ & 0.03 & $27.2 \pm 5.3$ & 0.95 \\
CIS concentration problems & $27.1 \pm 6.0$ & $27.2 \pm 5.7$ & 0.95 & $15.9 \pm 5.8$ & 0.77 \\
CIS reduced motivation & $15.4 \pm 6.3$ & $16.0 \pm 5.5$ & $16.6 \pm 4.2$ & $\mathbf{0 . 0 1}$ & $\mathbf{0 . 0 3}$ \\
CIS reduced physical activity & $13.7 \pm 4.3$ & $59.7 \pm 20.6$ & 0.12 & $55.0 \pm 20.3$ & 0.53 \\
SF-36 physical functioning & $51.4 \pm 19.8$ & $52.4 \pm 23.6$ & 0.46 & $49.5 \pm 24.5$ & 0.83 \\
SF-36 bodily pain & $48.1 \pm 21.4$ & $55.1 \pm 17.2$ & 0.22 & $57.1 \pm 14.0$ & 0.12 \\
SF-36 social functioning & $48.3 \pm 22.4$ & & & \\
\hline
\end{tabular}

Values represent mean (standard deviation) for continuous variables and number (percentage) for categorical variables. $P$ values are for comparisons with the study of Nijs et al. using a two-sided $t$-test. Statistically significant results are bold-faced

CIS Checklist individual strength, SF36 short form health survey 36 
Heins, M., Knoop, H., Nijs, J., Feskens, R., Meeus, M., Moorkens, G., Bleijenberg, G. Influence of symptom expectancies on stair-climbing performance in chronic fatigue syndrome: effect of study context. International Journal of Behavioral Medicine: 2013, 20(2), 213-218

Table 2 Results of stair-climbing task

\begin{tabular}{|c|c|c|c|c|c|}
\hline Descriptive variable & Nijs et al. $(n=21)$ & Current study $(n=49)$ & $\begin{array}{l}p \text { Value Nijs } \\
\text { vs. current }\end{array}$ & $\begin{array}{l}\text { Current (women) } \\
(n=30)\end{array}$ & $\begin{array}{l}p \text { Value Nijs vs. } \\
\text { current (women) }\end{array}$ \\
\hline Stair-climbing duration (min) & $85.2 \pm 20.0$ & $51.3 \pm 11.0$ & $<0.001$ & $51.5 \pm 11.1$ & $<0.001$ \\
\hline Heart rate at end of stair climbing (bpm) & $120.2 \pm 17.6$ & $120 \pm 16.7$ & 0.97 & $126.8 \pm 16.1$ & 0.18 \\
\hline Heart rate increase during stair climbing (bpm) & $35.6 \pm 12.5$ & $40.9 \pm 13.2$ & 0.12 & $46.7 \pm 11.9$ & 0.003 \\
\hline Experienced fatigue at baseline (mm) & $54.7 \pm 21.6$ & $58.2 \pm 17.9$ & 0.52 & $60.6 \pm 18.8$ & 0.32 \\
\hline Anticipated fatigue following stair climbing (mm) & $59.9 \pm 29.0$ & $53.1 \pm 25.6$ & 0.41 & $60.8 \pm 24.9$ & 0.91 \\
\hline Experienced fatigue following stair climbing (mm) & $59.1 \pm 27.0$ & $59.9 \pm 21.6$ & 0.91 & $61.3 \pm 23.8$ & 0.77 \\
\hline$\Delta$ anticipated-experienced fatigue $(\mathrm{mm})$ & $-2.1 \pm 32.5$ & $-6.8 \pm 23.3$ & 0.55 & $-0.5 \pm 23.0$ & 0.85 \\
\hline Experienced pain at baseline (mm) & $49.1 \pm 29.7$ & $25.6 \pm 25.4$ & 0.002 & $29.2 \pm 28.0$ & 0.02 \\
\hline Anticipated pain following stair climbing (mm) & $49.3 \pm 27.4$ & $31.2 \pm 31.1$ & 0.002 & $35.1 \pm 32.0$ & 0.10 \\
\hline Experienced pain following stair climbing (mm) & $46.9 \pm 28.3$ & $28.2 \pm 32.6$ & 0.002 & $32.0 \pm 33.7$ & 0.05 \\
\hline$\Delta$ Anticipated-experienced pain $(\mathrm{mm})$ & $0.5 \pm 27.9$ & $3.0 \pm 17.8$ & 0.71 & $3.2 \pm 22.4$ & 0.71 \\
\hline TS-fatigue & $13.0 \pm 4.6$ & $13.7 \pm 3.9$ & 0.47 & $13.8 \pm 3.9$ & 0.45 \\
\hline J-FCS & $0.9 \pm 0.5$ & $1.23 \pm 0.5$ & 0.02 & $1.26 \pm 0.5$ & 0.02 \\
\hline
\end{tabular}

Statistically significant results are bold-faced

$J$-FCS Jacobsen fatigue catastrophising scale, TS-fatigue Tampa scale fatigue

Table 3 Rank correlations of stair-climbing duration with symptom expectancies and psychological factors

Statistically significant results are bold-faced

$J-F C S$ Jacobsen fatigue catastrophising scale, TS fatigue Tampa scale fatigue, TSK Tampa scale kinesiophobia

Table 4 Results of the multiple regression analysis on duration of stair climbing

\begin{tabular}{llll}
\hline \multicolumn{4}{l}{$\rho(p$ Value $)$} \\
\cline { 2 - 4 } & Nijs et al. $(n=21)$ & Current study $(n=49)$ & Current (women) $(n=30)$ \\
\hline Anticipated fatigue & $0.17(0.49)$ & $\mathbf{0 . 4 0}(<\mathbf{0 . 0 0 1 )}$ & $\mathbf{0 . 4 3}(\mathbf{0 . 0 2})$ \\
Anticipated pain & $0.40(0.09)$ & $0.25(0.08)$ & $0.02(0.91)$ \\
$\Delta$ anticipated-experienced fatigue & $-0.08(0.72)$ & $\mathbf{0 . 3 0}(\mathbf{0 . 0 4})$ & $0.08(0.68)$ \\
$\Delta$ anticipated-experienced pain & $0.22(0.35)$ & $0.02(0.88)$ & $-0.24(0.21)$ \\
TSK & $\mathbf{0 . 5 7 ( 0 . 0 0 9 )}$ & $0.24(0.13)$ & $0.20(0.34)$ \\
TS-fatigue & $\mathbf{0 . 6 2 ( 0 . 0 0 3 )}$ & $0.28(0.06)$ & $0.19(0.32)$ \\
J-FCS & $\mathbf{0 . 6 7}(\mathbf{0 . 0 0 1 )}$ & $0.04(0.81)$ & $0.12(0.54)$ \\
\hline
\end{tabular}

\begin{tabular}{|c|c|c|c|c|c|}
\hline & \multicolumn{2}{|c|}{ Unstandardised coefficients } & \multicolumn{3}{|c|}{ Standardised coefficients } \\
\hline & $B$ & Standard error & Beta & $T$ & Significance \\
\hline Anticipated fatigue & 0.24 & 0.06 & 0.59 & 3.98 & $<0.001$ \\
\hline Fatigue before stair climbing & -0.12 & 0.08 & -0.21 & -1.48 & 0.15 \\
\hline Age (years) & 0.23 & 0.14 & 0.22 & 1.62 & 0.11 \\
\hline Sex (male) & 0.77 & 3.59 & 0.03 & 0.21 & 0.83 \\
\hline Body mass index $\left(\mathrm{kg} / \mathrm{m}^{2}\right)$ & -0.50 & 0.30 & -0.22 & -1.67 & 0.10 \\
\hline (Constant) & 48.66 & 9.41 & & 5.17 & $<0.001$ \\
\hline
\end{tabular}

